\title{
Oral microbiota in the oral-genitourinary axis: identifying periodontitis as a potential risk of genitourinary cancers
}

\author{
Shuai Yuan ${ }^{1}$, Cheng Fang ${ }^{1}$, Wei-Dong Leng ${ }^{2}$, Lan Wu ${ }^{3}$, Bing-Hui Li ${ }^{1,4}$, Xing-Huan Wang ${ }^{1,4^{*}}$, Hailiang Hu ${ }^{5,6^{*}}$ and \\ Xian-Tao Zeng ${ }^{1,4^{*}}$ (1)
}

\begin{abstract}
Periodontitis has been proposed as a novel risk factor of genitourinary cancers: although periodontitis and genitourinary cancers are two totally distinct types of disorders, epidemiological and clinical studies, have established associations between them. Dysbiosis of oral microbiota has already been established as a major factor contributing to periodontitis. Recent emerging epidemiological evidence and the detection of oral microbiota in genitourinary organs indicate the presence of an oral-genitourinary axis and oral microbiota may be involved in the pathogenesis of genitourinary cancers. Therefore, oral microbiota provides the bridge between periodontitis and genitourinary cancers. We have carried out this narrative review which summarizes epidemiological studies exploring the association between periodontitis and genitourinary cancers. We have also highlighted the current evidence demonstrating the capacity of oral microbiota to regulate almost all hallmarks of cancer, and proposed the potential mechanisms of oral microbiota in the development of genitourinary cancers.
\end{abstract}

Keywords: Oral microbiota, Oral-genitourinary axis, Periodontitis, Urogenital neoplasms, Prostatic neoplasms, Kidney neoplasms, Urinary bladder neoplasms

\section{Background}

Periodontal disease is an inflammatory and multifactorial chronic immunological disease consisting of two main subtypes, gingivitis and periodontitis [1-4]. Gingivitis is a reversible inflammation of the gingiva (gums, soft tissue surrounding the teeth) alone while periodontitis is characterized by permanent loss of periodontal tissue support [5]. In particularly susceptible individuals with compromised immune systems, gingivitis progresses to periodontitis, a chronic, irreversible breakdown of soft

\footnotetext{
*Correspondence: wangxinghuan1695@163.com; huhl@sustech.edu.cn zengxiantao1128@whu.edu.cn; zengxiantao1128@163.com

${ }^{1}$ Center for Evidence-Based and Translational Medicine, Zhongnan Hospital of Wuhan University, Wuhan 430071, Hubei, China

${ }^{6}$ School of Medicine, Southern University of Science and Technology, Shenzhen 518055, China

Full list of author information is available at the end of the article
}

and hard tissues surrounding the teeth [1-4]. Periodontitis has been raised as a public health problem: an estimated $42.2 \%$ of dentate adults aged 30 years or older in the United States have periodontitis, with $7.8 \%$ having severe periodontitis [6]. The prevalence of severe periodontitis varies in different countries and affects $11 \%$ of the global population [7]. Numerous studies have established associations between periodontitis and many systemic diseases, including cancer [8-12]. However, the precise mechanisms underlying these relationships remain unclear. As dysbiosis of oral microbiota has been involved in the pathogenesis of both periodontitis and systemic diseases, the causative link between periodontitis and systemic diseases, including cancer, through oral microbiota is being extensively explored $[13,14]$.

The microbiota present in tissues or mucosal sites have been shown to be involved in carcinogenesis and original author(s) and the source, provide a link to the Creative Commons licence, and indicate if changes were made. The images or other third party material in this article are included in the article's Creative Commons licence, unless indicated otherwise in a credit line to the material. If material is not included in the article's Creative Commons licence and your intended use is not permitted by statutory regulation or exceeds the permitted use, you will need to obtain permission directly from the copyright holder. To view a copy of this licence, visit http://creativecommons.org/licenses/by/4.0/. The Creative Commons Public Domain Dedication waiver (http://creativeco mmons.org/publicdomain/zero/1.0/) applies to the data made available in this article, unless otherwise stated in a credit line to the data. 
modulate the responses to cancer therapy $[15,16]$. The oral cavity is connected to the respiratory tract and acts as the entry portal for the gastrointestinal tract. Oral microbiota residing in the oral cavity have the opportunity to enter the respiratory and gastrointestinal tract. Thus, it is not surprising that dysbiosis of oral microbiota in periodontal disease, especially in periodontitis, can contribute to cancers of the gastrointestinal and respiratory tract, such as head and neck squamous cell carcinoma, lung cancer, pancreatic cancer, gastric cancer, and colorectal cancer [17-22]. In addition to the above tumors, emerging epidemiological evidence suggests that periodontitis is also associated with the risk of genitourinary cancers, such as prostate and bladder cancer [23, 24]. The recent discovery of pathogenic bacterial infections in genitourinary cancers highlights the tumor-promoting effect of the microbiome in prostate, bladder, and kidney cancers [25]. Ten hallmarks of cancer have been proposed by Hanahan and Weinberg to better our understanding of the complex multistep changes occurring during cancer development [26, 27]. These cancer hallmarks can basically be considered as the consequence of the tumor and tumor microenvironment interactions and the microbiota has been shown to be an important player in the homeostasis of the tumor-microenvironment, thus modulating almost all cancer hallmarks [28]. Given that oral microbiota can be detected in the genitourinary system [29], it is highly likely that they may promote the progression of genitourinary cancers and therefore provide the bridge between periodontitis and genitourinary cancers.

In this narrative review, we will summarize the epidemiological studies exploring the association between periodontitis and genitourinary cancers and highlight the current evidence for oral microbiota regulating the hallmarks of cancer, which may suggest the potential molecular mechanisms of oral microbiota in genitourinary cancers.

\section{Methods}

The aims of this narrative review are to: (1) review epidemiologic studies exploring the association between periodontitis and genitourinary cancers; (2) review the potential mechanisms of oral microbiota in genitourinary cancers. According to the National Cancer Institute (NCI) [30], genitourinary cancers comprise cancers found in the urinary system and the male reproductive system, including bladder cancer, kidney (renal cell) cancer, penile cancer, prostate cancer, transitional cell cancer of the renal pelvis and ureter, testicular cancer, urethral cancer, Wilms tumor, and other childhood kidney tumors.
To review epidemiologic studies exploring the association between periodontitis and genitourinary cancers we used the following inclusion criteria: (1) Participants: bladder cancer, kidney (renal cell) cancer, penile cancer, prostate cancer, transitional cell cancer of the renal pelvis and ureter, testicular cancer, urethral cancer, Wilms tumor, and other childhood kidney tumors; (2) Exposure: periodontitis, periodontal disease; (3) Control: without periodontal disease; (4) Outcome: initiation (incidence, formation of new tumors) and progression (further development of already existing tumors) of genitourinary cancers; (5) Study design: cohort study or case-control study. Cross-sectional studies were excluded. In the literature we searched, human papillomavirus (HPV) infections were sexually transmitted and were likely to be transient members of the oral microbiota. Although HPV could be detected in oral and genitourinary cancers, HPV was not in the scope of our review. Apart from HPV, we did not find any evidence that oral microbiota linked periodontitis to penile cancer, transitional cell cancer of the renal pelvis and ureter, testicular cancer, urethral cancer, Wilms tumor or childhood kidney tumors. Therefore, we only focused on prostate cancer, bladder cancer and kidney cancer in this review.

To review the potential mechanisms of oral microbiota in genitourinary cancers. We conducted a literature search using PubMed, Embase and Web of Science to identify relevant research studies and review articles published in English up to December 2020 using the following keywords: periodontal disease, periodontitis, periodontal bacteria, periodontal pathogens, oral pathogens, oral microbiota, oral microbiome, oral microflora, oral bacteria, subgingival microflora, cancer, genitourinary cancers, prostate cancer, bladder cancer, urothelial carcinoma, kidney cancer, and renal cell carcinoma. We focused on in vitro and in vivo studies to propose the potential mechanisms of oral microbiota in the development of genitourinary cancers.

\section{Epidemiological associations between periodontitis and genitourinary cancers}

The link between periodontitis and increased risk of genitourinary cancers has been established by epidemiological and clinical studies, suggesting that periodontitis is a novel risk factor for genitourinary cancers (Table 1). Many epidemiological studies have not clearly distinguished between gingivitis and periodontitis, which were collectively referred to as periodontal diseases. However, it is not likely that simple marginal gingivitis caused by supragingival plaque has much systemic effect, except for some inflammatory biomarkers that may be found in both the gingiva and the bloodstream. Periodontitis, by contrast, is accompanied by the pathogenic 


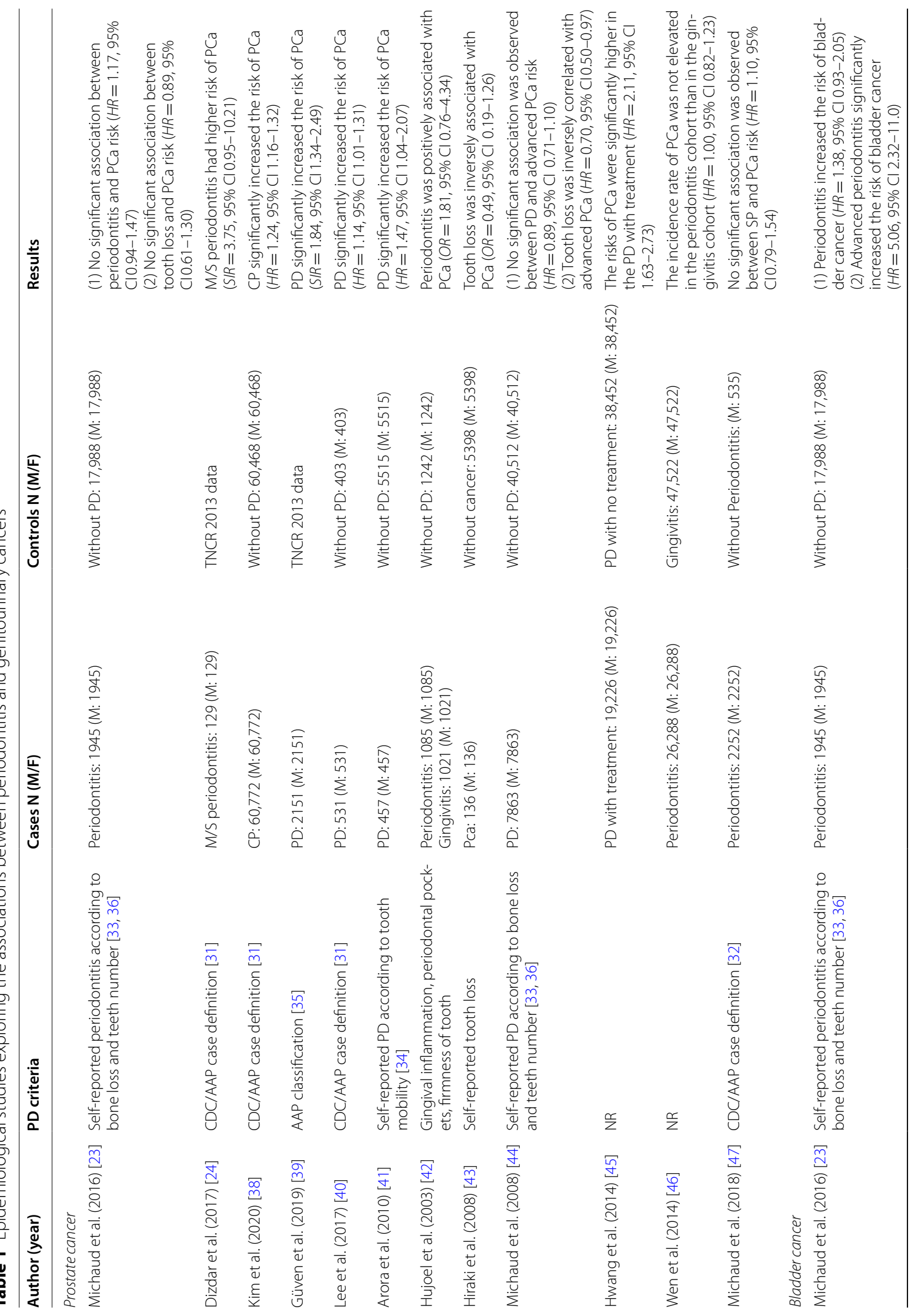




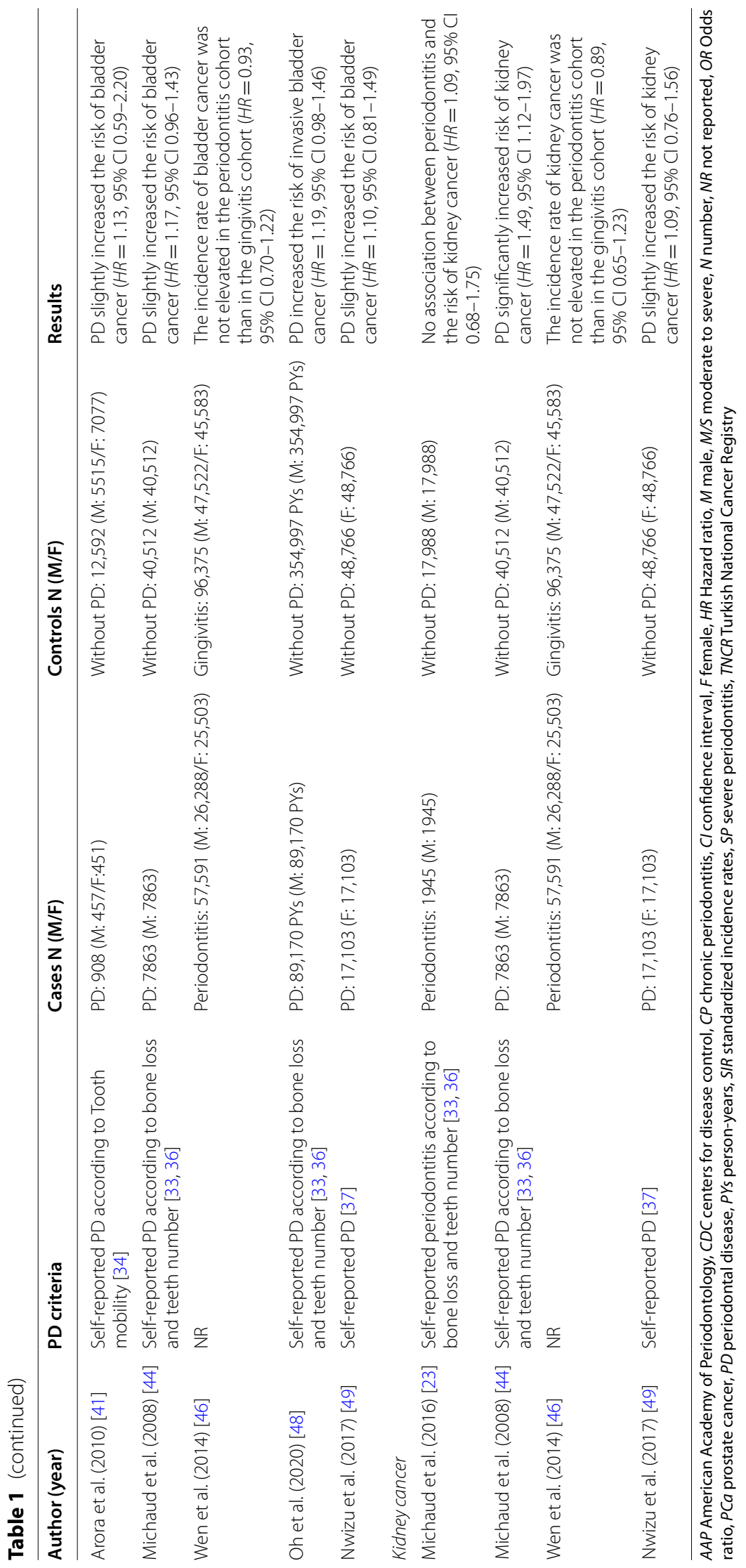


anaerobic bacteria that are usually reported to be associated with remote tumors and tumorigenesis. It should also be noted that there was not any global definition of periodontitis until the Centers for Disease Control and Prevention (CDC) and the American Academy of Periodontology (AAP) published such classifications for population-based surveillance in 2007 (no/mild, moderate, and severe periodontitis) [31] and in 2012 (no, mild, moderate, and severe periodontitis) [32]. Such a lack of case definitions leads to the heterogeneity of the definition of periodontitis in population-based studies [31-37], which could hamper establishing epidemiological associations between periodontitis and genitourinary cancers.

\section{Prostate cancer}

Mounting evidence suggests that periodontitis may be a potential risk for prostate cancer. A recent cohort study evaluated the cancer risk in patients with chronic periodontitis and suggested that chronic periodontitis significantly increased the risk of prostate cancer [hazard ratio $(H R)=1.24$, 95\% confidence interval (CI) 1.16-1.32] [38]. Two studies in Turkey also found significant correlations between periodontal disease (especially moderate-severe periodontitis) and prostate cancer [24, 39]. Another retrospective cohort study found that periodontal disease increased the risk of prostate cancer by $14 \%(H R=1.14$, 95\% CI 1.01-1.31) after adjustment for sociodemographic factors, comorbidities, smoking status, alcohol intake, and regular exercise [40]. One prospective cotwin study reported an association of periodontal disease with the increased risk of prostate cancer $(H R=1.47,95 \%$ CI 1.04-2.07) [41] and another study suggested individuals with periodontitis had elevated risk of prostate cancer [odds ratio $(O R)=1.81,95 \%$ CI 0.76-4.34] [42] (Table 1).

However, inverse associations or no associations between periodontitis and risk of prostate cancer have also been identified in several studies. One case-control study found tooth loss was inversely associated with the risk of prostate cancer $(O R=0.49,95 \%$ CI $0.19-1.26)$ [43] and another study also reported a significant inverse association between tooth loss and advanced prostate cancer $(H R=0.70,95 \%$ CI 0.51-0.97) [44]. Tooth loss can be caused not only by periodontitis but also by caries, trauma, and other reasons, which may have led to these inconsistent epidemiological findings. To complicate the results of association, one study found a significantly higher risk for prostate cancer following the treatment of periodontal disease, supporting the inverse association between periodontal disease and prostate cancer [45]. Several studies have found no associations between periodontitis and the risk of prostate cancer [23, 46, 47] (Table 1). The discrepancy of the findings may be attributed to many factors, such as the different clinical criteria for the diagnosis of periodontitis and the confounders in the epidemiological studies [23, 39, 40, 44].

\section{Bladder cancer}

Periodontitis may also influence the risk of bladder cancer. A recent prospective study found a high risk of bladder cancer in men with a history of periodontal disease alone $(H R=1.19,95 \%$ CI 0.98-1.46), and a higher bladder cancer risk in men with a history of both peptic ulcer and periodontal disease $(H R=1.52,95 \%$ CI $1.05-2.20)$ [48]. Prior to this study, four prospective cohort studies revealed a positive but non-significant association of periodontitis (or periodontal disease) with the risk of bladder cancer [23, 41, 44, 49]. One retrospective cohort study, which is as controversial as risks for prostate cancer, did not find any association between periodontitis and the risk of bladder cancer [46] but advanced periodontitis in people who had never smoked was associated with an elevated risk of bladder cancer $(\mathrm{HR}=5.06,95 \%$ CI 2.32-11.0) [23] (Table 1).

\section{Kidney cancer}

At present, there are relatively few studies reporting on the effects of periodontitis on kidney cancer (Table 1). Michaud et al. reported that periodontal disease was positively associated with the risk of kidney cancer in the Health Professionals Follow-up Study [44]. However, after an additional 8 years of follow-up in the same cohort, no associations were observed between periodontitis and the risk of kidney cancer among males who had never smoked [23]. Another two studies also found the incidence rate of kidney cancer was not elevated in the periodontitis (or periodontal disease) cohort [46, 49] (Table 1). Further studies are needed to examine the correlation between periodontitis and kidney cancer.

\section{Dysbiosis of oral microbiota in periodontitis}

The microorganisms living in the oral cavity have been referred to as the oral microbiota, oral microflora, or oral microbiome $[50,51]$. The homeostasis established by oral microbiota is important in maintaining oral health (Fig. 1) [28, 52]. Over 2000 different microbial taxa, including bacteria, fungi, protozoa, archaea and viruses, have been detected in the human oral cavity [53]. Among them, bacteria are the most abundant taxonomic group and are usually highly organized in oral biofilms on the oral surfaces [54]. Compared to the oral mucosa, the oral biofilms on the dental surface (known as dental plaque biofilms) contain a higher microbial load and are more essential to maintaining oral health, as the oral mucosa are covered by epithelial cells and are frequently shed [54, 55]. By using $16 \mathrm{~s}$ ribosomal RNA (rRNA) sequencing, the Human Microbiome Project (HMP) has explored the 


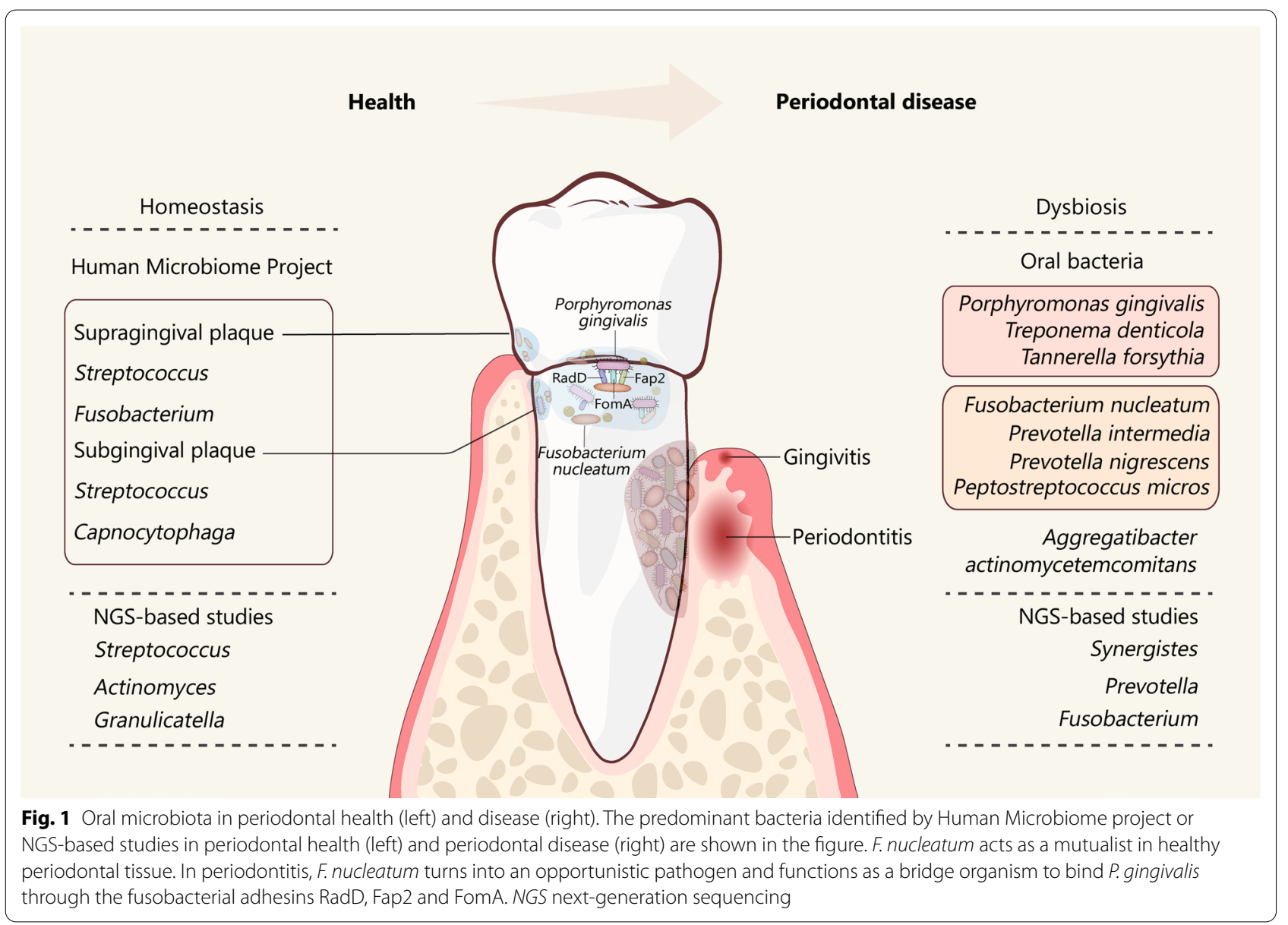

microbiome in each oral habitat in healthy individuals and found that the predominant genera of the subgingival plaque, in terms of dental plaque biofilm, are Streptococcus and Fusobacterium whereas the predominant genera of the supragingival plaque are Streptococcus and Capnocytophaga [56]. With the further extensive application of next-generation sequencing (NGS) techniques, the composition of microbiota related to periodontal health and periodontal disease has also been identified (Fig. 1). For example, the genera Streptococcus, Actinomyces, and Granulicatella are associated with periodontal health, whereas the genera Synergistes, Prevotella and Fusobacterium are associated with periodontitis [57-60]. The NGS-based studies have also revealed that uncultivable and/or rare oral microbiota, such as Methanobrevibacter oralis, Methanobacterium curvum/congolense, and Methanosarcina mazeii are present in both periodontitis and periodontally healthy subjects $[61,62]$. Among these attached microbes in dental plaque, Fusobacterium nucleatum (F. nucleatum) can function as a bridging organism to connect the primary colonizers such as Streptococcus and secondary colonizers like Porphyromonas gingivalis
(P. gingivalis) through the fusobacterial adhesins RadD, Fap2 and FomA [63]. Thus, F. nucleatum is a mutualist in healthy periodontal tissue playing a structurally supportive role in dental plaque biofilms but turns into an opportunistic pathogen leading to periodontitis under dysbiotic conditions (Fig. 1).

Studies have identified several species of oral bacteria, mainly gram-negative anaerobes, which are responsible for periodontitis (Fig. 1). These oral bacteria can be classified into five major complexes, namely the green, purple, yellow, orange, and red complexes [64-66]. The "red complex" and "orange complex" are commonly associated with periodontitis. The "red complex" species, consisting of P. gingivalis, Treponema denticola, and Tannerella forsythia, exhibit very strong associations with periodontitis, indicating that these pathogenic bacteria might be the primary pathogens in periodontitis. Many studies have been conducted to investigate the pathogenic mechanisms and characterize the virulence factors of the three pathogens. A "keystone-pathogen hypothesis" has been proposed in which P. gingivalis in the periodontium drives the progression of periodontitis [67]. 
P. gingivalis-derived gingipains, phosphoserine phosphatase SerB and lipopolysaccharide (LPS) are potent virulence factors, which can impair the innate host defense systems and induce a destructive response [68]. Gingipains are arginine-specific cysteine proteinases that can cleave complement component $\mathrm{C} 5$ into active fragments C5a locally and activate C5a receptors (C5aR) on leukocytes; $\mathrm{C} 5 \mathrm{aR}$ signaling then triggers inflammation and subverts leukocyte killing capacity [69]. Phosphoserine phosphatase SerB secreted by P. gingivalis contributes to the inhibition of IL-8, thus delaying the recruitment of neutrophils and leading to overgrowth of oral bacterial species [70]. LPS of $P$. gingivalis exhibits specific lipid A structures, which acts as a Toll-like receptor 4 (TLR4) antagonist to inhibit the activation of TLR4-dependent antimicrobial pathways in leukocytes [71]. The subversion of host defense caused by these virulence factors collectively lead to dysbiotic microbiota, inflammation and bone resorption, resulting in a self-feeding 'vicious cycle' [67]. Although the "red complex" species exert keystone effects in disruption of periodontal tissue homeostasis, the putative oral bacteria in the "orange complex" that consists of F. nucleatum, Prevotella intermedia, Prevotella nigrescens, and Peptostreptococcus micros, have moderately pathogenic effects on the development of periodontitis. For example, $F$. nucleatum can influence the secretion of inflammatory factors, including TNF- $\alpha$, IL-6 and IL-8, from immune cells or the oral epithelium $[72,73]$, and therefore modulates the host inflammatory response. $F$. nucleatumcan also interacts directly with $P$. gingivalis and increases the invasion ability of $P$. gingivalis [74]. Furthermore, the virulence properties of $P$. gingivalis can be enhanced by another "orange complex" organism: Peptostreptococcus micros through promoting the activity of $P$. gingivalis gingpains [75]. In addition to the above bacteria in the "red complex" and "orange complex", Aggregatibacter actinomycetemcomitans (A. actinomycetemcomitans) has been shown to cause periodontitis as well [76]. The virulence factors of A. actinomycetemcomitans such as leukotoxin, cytolethal distending toxin, and LPS, can cause tissue destruction and bone resorption by promoting inflammation and interacting with the immune system (Fig. 1).

\section{Regulation of hallmarks of cancer by oral microbiota}

The hallmarks of cancer have been well described by Hanahan and Weinberg, providing us with a remarkable insight into its complex biology [26, 27]. These hallmarks can be classified into two classes: dysfunctional intracellular signaling (including sustaining proliferative signaling, evading growth suppressors, resisting cell death, enabling replicative immortality, activating invasion and metastasis, reprogramming of energy metabolism, and genome instability and mutation) and intercellular signaling creating the tumor microenvironment (including angiogenesis, tumor-promoting inflammation, and evading immune destruction). Many studies have confirmed that oral microbiota could act as potential risk modifiers in the pathogenesis of various malignancies. Indeed, each of the hallmarks of cancer could be modulated by the oral microbiota. F. nucleatum and $P$. gingivalis are the two prominent oral bacteria that can modulate the hallmarks of cancer using different mechanisms (Fig. 2).

\section{Intracellular signaling}

Dysregulation of the intracellular signaling pathways of cancer cell leads them to constantly proliferate and evade cell death. Oral microbiota can interact with cells and affect cell proliferation and survival. For example, $F$. nucleatum expresses unique FadA adhesin, which activates $\beta$-catenin signaling by binding to E-cadherin [77]. The activation of $\mathrm{Wnt} / \beta$-catenin signaling promotes colorectal cancer cell proliferation and survival. $F$. nucleatum also activates $\beta$-catenin signaling through its LPS via a TLR4/P-PAK1/P- $\beta$-catenin S675 cascade in colorectal cancer cells (Fig. 2a) [78].

As well as sustaining proliferative signaling, the ability to evade growth suppression also allows cancer cells to constantly proliferate. The P53 tumor suppressor gene acts as a central node in regulating cell proliferation, which is often down regulated or mutated in cancer cells. P. gingivalis may induce mutations of the P53 tumor suppressor via peptidyl arginine deaminase (PAD) enzymes, thus accelerating the progression of the cell cycle in gastrointestinal cancer cells (Fig. 2b) [79]. Apart from $P$. gingivalis, oral bacteria like Prevotella intermedia, Tannerella forsythia, and Treponema denticola also possess the PAD enzyme which induces P53 mutations in pancreatic cancer [80].

In order to be immortal, cancer cells develop the ability to resist cell death. Apoptosis, autophagy and necrosis are three major pathways which control cell death [81]. $P$. gingivalis has been shown to influence cell death decisions by regulating apoptosis (Fig. 2c). Mechanistically, $P$. gingivalis can inhibit apoptosis at the level of mitochondria through the PI3K/Akt pathway [82]. The virulence factors of $P$. gingivalis, such as LPS and fimbriae regulate the PI3K/Akt pathway positively or negatively in different cells [83-86]. The proteolytic activity of gingipains also plays a critical role in disrupting the PI3K/Akt pathway during $P$. gingivalis infection [87]. Another mechanism of $P$. gingivalis in resisting cell death is through manipulation of the JAK/Stat pathway, which induces the intrinsic mitochondrial apoptosis pathway [88]. Accompanied by 


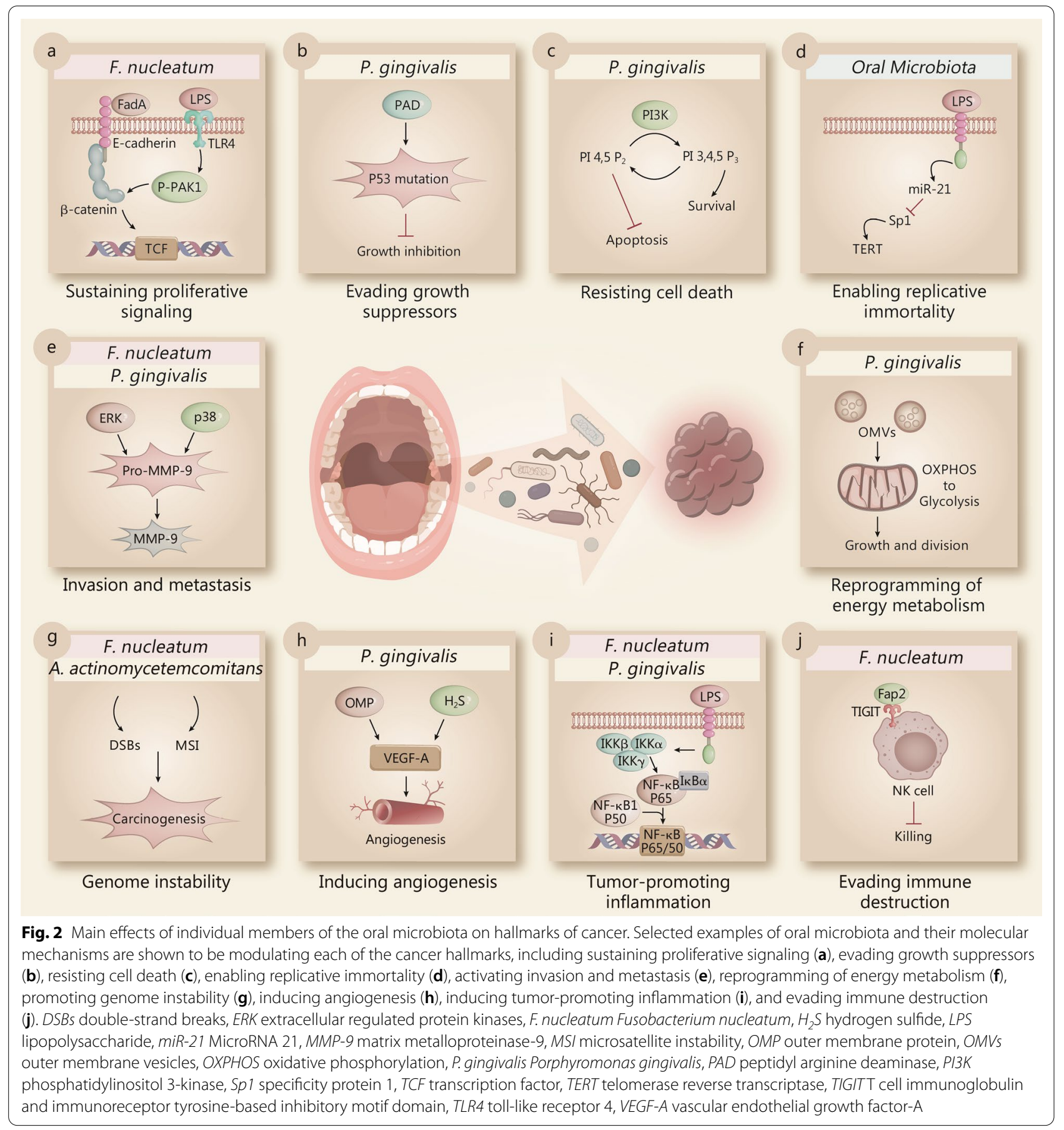

the changes in cellular signaling pathways, $P$. gingivalis also exerts its antiapoptotic effect by counterbalancing pro- and antiapoptotic members of the Bcl-2 family proteins [89]. The pro-apoptotic molecules such as Bad, Bax, and Bid are down regulated, whereas the antiapoptotic Bcl-2 is upregulated in the infected cells [90]. The purinergic receptor $\mathrm{P} 2 \mathrm{X} 7$ functions as an important mediator of apoptosis and the activation of the P2X7 receptor requires high concentrations of extracellular ATP [91]. P. gingivalis can secrete nucleoside diphosphate kinase (NDK), which can scavenge extracellular ATP, thus preventing P2X7-mediated apoptosis [92].

In line with the ability of unlimited proliferation, cancer cells require unlimited replicative potential. The number of cell division cycles in normal cells is limited due to the loss of telomeres after each cell division. In 
contrast to normal cells, cancer cells have unlimited replicative potential by expressing telomerase, which is able to maintain the stability of telomere DNA. Telomerase Reverse Transcriptase (TERT) is the most important component of the telomerase holoenzyme. Oral microbiota may regulate the expression of TERT via LPS induced miR-21 expression (Fig. 2d) [93].

Activating invasion and metastasis is another complex hallmark capability, contributing to local invasion and distant metastasis. The epithelial-mesenchymal transition (EMT) program broadly promotes invasion and metastasis in cancer cells. Oral bacteria, such as $P$. gingivalis and $F$. nucleatum, have the ability to induce EMT-like features and regulate the expression of markers in vitro [94, 95]. Matrix metalloproteinase-9 (MMP9) plays an important role in cell migration and invasion by degrading the basement membranes and extracellular matrix. P. gingivalis activates ERK1/2-Ets1, p38/HSP27, and PAR2/NF-kB pathways to promote the expression of pro-MMP-9 production. Furthermore, the pro-MMP-9 is subsequently cleaved into its mature active form MMP-9 by gingipains and promotes the invasion of oral squamous cell carcinoma (Fig. 2e) [96]. In addition to $P$. gingivalis, $F$. nucleatum also promotes the secretion of MMP-9, resulting in the activation of cell invasion and metastasis (Fig. 2e) [97].

Reprogramming of energy metabolism is an emerging hallmark of cancer. In order to provide enough energy for cell proliferation, tumor cells need to reprogram energy metabolism, which largely rely on glycolysis. Both $P$. gingivalis and its outer membrane vesicles (OMVs) can shift the energy metabolism from oxidative phosphorylation (OXPHOS) to glycolysis in macrophages (Fig. 2f) [98].

Genomic instability, such as microsatellite instability and chromosomal instability, is an enabling characteristic of most cancers that promotes tumor progression. A cross-sectional study showed that periodontitis could influence the DNA damage status, suggesting that oral microbiota may induce DNA damage and cause genome instability [99]. For example, A. actinomycetemcomitans infection can induce DNA double-strand breaks (DSBs) in host cells and subsequently increase the risk of tumorigenesis (Fig. 2g) [100]. F. nucleatum is detected in colorectal cancer tissues and is associated with high microsatellite instability (MSI-H) and a high CpG island methylation phenotype (CIMP) (Fig. 2g) [101].

\section{Intercellular signaling}

Angiogenesis is a prominent feature of cancer, which provides nutrients and oxygen for cancer cells and is key to the hematogenous metastatic process. VEGF-A (vascular endothelial growth factor-A) is a potential inducer of angiogenesis. The vesicle and outer membrane proteins
(OMP) from $A$. actinomycetemcomitans and $P$. gingivalis are able to stimulate VEGF-A expression levels in human gingival fibroblasts [102]. Oral bacteria (e.g., P. gingivalis, Prevotella intermedia, A. actinomycetemcomitans, and $F$. nucleatum) can produce volatile sulfur compounds (VSCs), such as hydrogen sulfide $\left(\mathrm{H}_{2} \mathrm{~S}\right)$, to promote angiogenesis that can provide the cancer cells with nutrients and oxygen (Fig. 2h) [103].

Inflammation has long been associated with cancer pathogenesis. Inflammation is stimulated by innateimmune receptors such as the Toll-like receptors (TLRs) [104]. The activation of inflammatory signals creates a tumor environment that promotes cancer formation and growth [105]. The NF- $\mathrm{KB}$ signaling pathway plays a vital role in activating a number of inflammatory genes [106]. The LPS from oral bacteria (including P. gingivalis and $F$. nucleatum) interacts with TLRs and induces innate immune pathways such as NF- $\mathrm{kB}$ signaling pathway (Fig. 2i) [107]. NF-kB signaling then activates several inflammatory bioactive molecules, including IL-6 that sustains proliferative signaling and resists cell death, VEGF that induces angiogenesis, metalloproteases that facilitate invasion and metastasis and reactive oxygen species (ROS) that lead to DNA damage [108]. Recently, Al-Hebshi et al. also suggested a new "passenger-turningdriver" functional model for the role of oral microbes in cancer pathogenesis, in which the oral microbes change their role as passive bystanders ("passengers") to active contributors to the tumorigenesis ("drivers") by sustaining chronic inflammation [109].

Immune surveillance acts as a barrier to tumor formation and progression, however, mounting evidence has shown that cancer cells are able to create an immunosuppressive microenvironment to evade immune destruction [110]. The oral microbiota also take part in tumor-host immunological interactions and facilitate cancer cells to evade immune destruction. For example, natural killer (NK) cell killing of cancer cells can be inhibited by $F$. nucleatum. Fap 2 protein of $F$. nucleatum directly interacted with $\mathrm{T}$ cell immunoglobulin and immunoreceptor tyrosine-based inhibitory motif domain (TIGIT), which leads to the delivery of an inhibitory signal in NK cells, subsequently leading to the inhibition of NK cell cytotoxicity (Fig. 2j) [111].

\section{Potential mechanisms of oral microbiota in genitourinary cancers}

Although oral microbiota has been demonstrated to modulate almost all the hallmarks of cancer in different types of cancers (Fig. 2), the contribution of oral microbiota to genitourinary cancers remains rather mechanistically speculative because genitourinary organs are far away from the periodontium where the oral microbiota 
originally reside. However, the epidemiological associations of periodontitis with the risk of genitourinary cancers and the detection of oral microbiota in genitourinary organs indicate the presence of the oral-genitourinary axis and oral microbiota may play roles in the initiation and progression of genitourinary cancers. Despite many pieces of evidence exploring the capability of oral microbiota to regulate the hallmarks of cancer, few direct in vitro and in vivo studies have explored the possibility that oral microbiota could influence the development of genitourinary cancers. Therefore, we proposed several causative factors derived from oral microbiota that may act on genitourinary cancers in a direct way through oral bacteria's structural components or their metabolites and/or an indirect way through systemic inflammation (Fig. 3).

\section{Direct effect of oral microbiota and its metabolites}

The conventional view assumes that the urinary system is sterile. However, recent studies have revealed that microbial populations are present in the urinary system, which are described as the "urinary microbiome". A specific urinary microbiome of urine has been reported among healthy individuals and its composition can change with the progression of genitourinary malignancies [25]. Accumulating evidence supports the spread of the oral bacteria through transient bacteremia, resulting in bacterial colonization in a distant organ. For example, $P$. gingivalis, A. actinomycetemcomitans and Treponema denticola were detected in atherosclerotic plaques, suggesting that oral bacteria could enter into the bloodstream and colonize distant areas of the cardiovascular system [112]. Placental colonization with oral bacteria, such as $P$. gingivalis and F. nucleatum, provides evidence that oral bacteria can cross the placental barrier and cause adverse pregnancy outcomes $[113,114]$. Oral $P$. gingivalis infection in mice can cross the blood-brain barrier, leading to brain colonization and the increase of amyloid plaques in the brain, which also supports the association of Alzheimer's disease with chronic periodontitis [115]. In the urinary system, Estemalik et al. found that oral bacteria, such as $P$. gingivalis, Prevotella intermedia, and

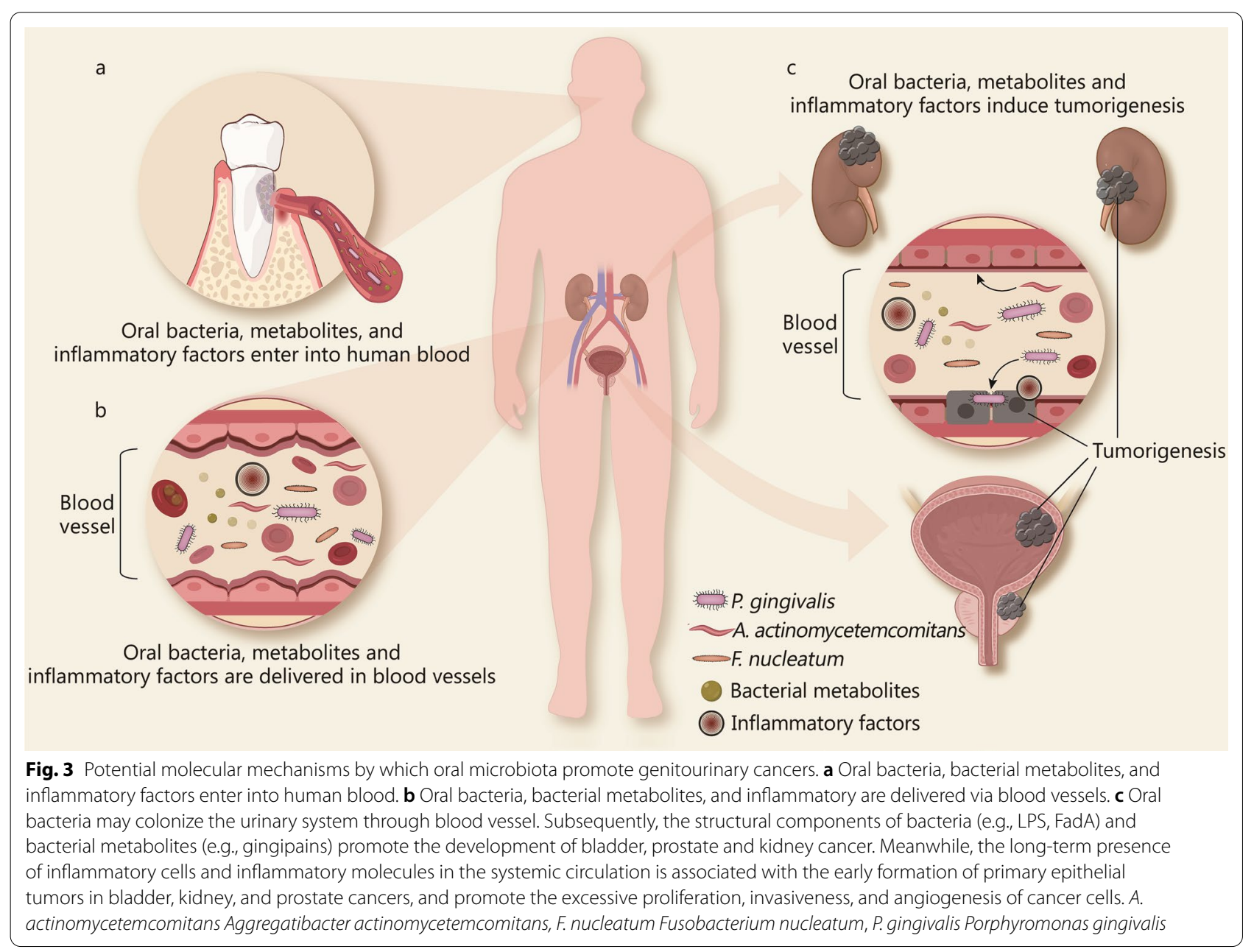


Treponema denticola, can be detected in the prostatic secretions of patients with periodontitis [29], suggesting that they may colonize the urinary system via the blood vessels. Subsequently, the structural components of bacteria (e.g., LPS, FadA) and bacterial metabolites (e.g. gingipains) may be involved in promoting the development of prostate, bladder and kidney cancer (Fig. 3). An animal model study has shown that injecting LPS derived from $P$. gingivalis intraperitoneally into mice can induce the overexpression of Saa3, Ticam2, Reg3b, Oxct2a, and Xcr1 in the kidney and these genes regulate a variety of important biological processes, including cell adhesion, apoptosis, immune responses and inflammation, which may regulate the different hallmarks of genitourinary cancers [116]. Several in vitro studies have also shown that $P$. gingivalis and Treponema denticola can degrade the epithelial cell-cell junction complexes in Madin-Darby canine kidney (MDCK) cells by regulating EMT markers (like E-cadherin and ZO-1), and therefore may contribute to cell invasion and metastasis of genitourinary cancers $[117,118]$. It should be pointed out that even though oral bacteria are found in the urinary system, they may have been passive bystanders brought to the urinary system via bacteremia. More studies are needed to detect the metabolites of oral microbiota in the urinary system in order to claim they have been alive and possibly played a role in genitourinary cancers.

\section{Indirect effect of systemic inflammation}

Periodontitis is known as an inflammatory disease that can lead to systemic inflammation [119]. Chronic inflammation is a well-known risk factor for cancer, which affects its development at different stages [120]. In genitourinary cancers, inflammatory cells (like mast cells, granulocytes, NK cells, and lymphocytes) and inflammatory molecules (like IL-6, IL-1 $\beta$, TNF- $\alpha$, and TGF- $\beta$ ) play important roles in the transformation, proliferation, invasion, metastasis, and angiogenesis of cancer cells [121-123]. Of particular note, the progression model for prostate cancer has been proposed, which highlights the vital function of inflammation in prostate cancer [124]. In this model, chronic prostatitis is accompanied with inflammatory cell infiltration, which can lead to proliferative inflammatory atrophy (PIA). PIA may progress to prostatic intraepithelial neoplasia (PIN) under the continuous stimulation of inflammation, and eventually it evolves into prostate cancer. The virulence factors of oral microbiota, such as LPS or gingipains in the oral cavity, could activate innate immune pathways by binding TLR and then induce the activation of a wide range of inflammatory pathways (like NF-kB signaling pathway and PI3K/Akt signaling pathway) in the immune cells. Subsequently, pro-inflammatory molecules such as IL-6,
IL-1 $\beta$, TNF- $\alpha$, PGE2, or MMPs are secreted into the systemic circulation by immune cells [125]. Meanwhile, inflammatory cells may also enter into bloodstream leading to an inflammatory cell infiltration in a distant organ [126]. The long-term presence of inflammatory cells and inflammatory molecules in the systemic circulation is associated with the early formation of primary epithelial tumors in bladder, kidney, and prostate cancers, and promotes the excessive proliferation, invasiveness, and angiogenesis of cancer cells. Thus, the systemic inflammation processes caused by oral microbiota may partly interpret the crosstalk between periodontitis and genitourinary cancers (Fig. 3).

\section{Conclusions}

The research on the relationship between periodontitis and genitourinary cancers is still in its infancy, with only a handful epidemiological studies available supporting this view. Oral microbiota may regulate the hallmarks of cancer through direct effects (structural components and metabolites) or indirect effects (systemic inflammation), and subsequently promote the tumorigenesis and progression of prostate, bladder and kidney cancer. Culture- and molecular-based detections of oral microbiota in genitourinary cancers shed new light on the direct relationship between periodontitis and genitourinary cancers and may suggest the detection of oral microbiota as new biomarkers to predict genitourinary cancers in patients with periodontitis. Further studies to explore the biological function and underlying mechanisms of oral microbiota in genitourinary cancers would also open new avenues for cancer therapy by targeting oral microbiota.

\section{Abbreviations \\ A. actinomycetemcomitans: Aggregatibacter actinomycetemcomitans; Akt: \\ Protein kinase B; ATP: Adenosine triphosphate; Bad: BCL2 associated agonist of cell death; Bax: BCL2-associated X; Bcl-2: B-cell lymphoma-2; Bid: $\mathrm{BH} 3$ interact- ing domain death agonist; $C 5 a R$ : C5a receptor; CIMP: CpG island methyla- tion phenotype; DSBs: Double-strand breaks; EMT: Epithelial-mesenchymal transition; F. nucleatum: Fusobacterium nucleatum; $\mathrm{H}_{2} \mathrm{~S}$ : Hydrogen sulfide; HMP: Human Microbiome Project; IL-6: Interleukin-6; IL-8: Interleukin-8; JAK: Janus kinase; LPS: Lipopolysaccharide; MDCK: Madin-Darby canine kidney; MMP-9: Matrix metalloproteinase-9; MSI-H: High microsatellite instability; NDK: Nucleoside diphosphate kinase; NGS: Next-generation sequencing; NK: Natu- ral killer; NCl: National Cancer Institute; OMP: Outer membrane protein; OMVs: Outer membrane vesicles; OXPHOS: Oxidative phosphorylation; P. gingivalis: Porphyromonas gingivalis; P2X7: P2X Purinoceptor 7; PAD: Peptidyl arginine deaminase; PI3K: Phosphatidylinositol 3-kinase; PIA: Proliferative inflammatory atrophy; PIN: Prostatic intraepithelial neoplasia; ROS: Reactive oxygen species; rRNA: Ribosomal RNA; Stat: Signal transducer and activator of transcription; TERT: Telomerase Reverse Transcriptase; TIGIT: T cell immunoglobulin and immunoreceptor tyrosine-based inhibitory motif domain; TLR4: Toll-like receptor 4; TLRs: Toll-like receptors; TNF-a: Tumor necrosis factor alpha; VEGF-A: Vascular endothelial growth factor-A; VSCs: Volatile sulfur compounds.}

\section{Acknowledgements}

Not applicable. 


\section{Authors' contributions}

XTZ, XHW and HH conceived and designed the review. XTZ, SY, and LW drafted the manuscript and prepared figures and table. WDL, BHL and CF undertook the initial research and discussed the manuscript. XHW and $\mathrm{HH}$ reviewed and revised the manuscript. All authors read and approved the final manuscript.

\section{Funding}

This work was supported by the Zhongnan Hospital of Wuhan University Science, Technology and Innovation Seed Fund (No. znpy2019011), the Fundamental Research Funds for the Central Universities (No. 2042020kf0130), the Nature Science Foundation of Hubei Province (No. 2019FFB03902), and the Health Commission of Hubei Province Scientific Research Project (No. WJ2019H035).

\section{Availability of data and materials}

Not applicable.

\section{Declarations}

Ethics approval and consent to participate

Not applicable.

\section{Consent for publication}

Not applicable.

\section{Competing interests}

The authors declare that they have no competing interests.

\section{Author details}

${ }^{1}$ Center for Evidence-Based and Translational Medicine, Zhongnan Hospital of Wuhan University, Wuhan 430071, Hubei, China. ${ }^{2}$ Department of Stomatology, Taihe Hospital, Hubei University of Medicine, Shiyan 442000, Hubei, China. ${ }^{3}$ Department of Stomatology, Zhongnan Hospital of Wuhan University, Wuhan 430071, Hubei, China. ${ }^{4}$ Department of Urology, Zhongnan Hospital of Wuhan University, Wuhan 430071, Hubei, China. ${ }^{5}$ Department of Pathology, Duke University School of Medicine, Durham, NC 27710, USA. ${ }^{6}$ School of Medicine, Southern University of Science and Technology, Shenzhen 518055, China.

Received: 15 February 2021 Accepted: 3 September 2021

Published online: 29 September 2021

\section{References}

1. Kinane DF, Stathopoulou PG, Papapanou PN. Periodontal diseases. Nat Rev Dis Primers. 2017;3:17038.

2. Pihlstrom BL, Michalowicz BS, Johnson NW. Periodontal diseases. Lancet. 2005;366(9499):1809-20.

3. Armitage GC. Periodontal diagnoses and classification of periodontal diseases. Periodontol. 2000;2004(34):9-21.

4. Highfield J. Diagnosis and classification of periodontal disease. Aust Dent J. 2009;54(Suppl 1):S11-26. https://doi.org/10.1111/j.1834-7819. 2009.01140.x.

5. Peres MA, Macpherson LMD, Weyant RJ, Daly B, Venturelli R, Mathur $M R$, et al. Oral diseases: a global public health challenge. Lancet. 2019:394(10194):249-60.

6. Eke PI, Thornton-Evans GO, Wei L, Borgnakke WS, Dye BA, Genco RJ. Periodontitis in US adults: national health and nutrition examination survey 2009-2014. J Am Dent Assoc. 2018;149(7):576-88.

7. Kassebaum NJ, Bernabe E, Dahiya M, Bhandari B, Murray CJ, Marcenes W. Global burden of severe periodontitis in 1990-2010: a systematic review and meta-regression. J Dent Res. 2014;93(11):1045-53.

8. Nadim R, Tang J, Dilmohamed A, Yuan S, Wu C, Bakre AT, et al. Influence of periodontal disease on risk of dementia: a systematic literature review and a meta-analysis. Eur J Epidemiol. 2020;35(9):821-33.

9. Herrera D, Molina A, Buhlin K, Klinge B. Periodontal diseases and association with atherosclerotic disease. Periodontol 2000. 2020;83(1):66-89.

10. Bobetsis YA, Graziani F, Gürsoy M, Madianos PN. Periodontal disease and adverse pregnancy outcomes. Periodontol 2000. 2020;83(1):154-74.
11. Nwizu N, Wactawski-Wende J, Genco RJ. Periodontal disease and cancer: epidemiologic studies and possible mechanisms. Periodontol 2000 2020:83(1):213-33.

12. Fang $C$, Wu L, Zhu C, Xie WZ, Hu H, Zeng XT. A potential therapeutic strategy for prostatic disease by targeting the oral microbiome. Med Res Rev. 2021;41(3):1812-34.

13. Curtis MA, Diaz PI, Van Dyke TE. The role of the microbiota in periodontal disease. Periodontol 2000. 2020;83(1):14-25.

14. Zanetta P, Squarzanti DF, Sorrentino R, Rolla R, Aluffi Valletti P, Garzaro $M$, et al. Oral microbiota and vitamin D impact on oropharyngeal squamous cell carcinogenesis: a narrative literature review. Crit Rev Microbiol. 2021;47(2):224-39.

15. Louis P, Hold GL, Flint HJ. The gut microbiota, bacterial metabolites and colorectal cancer. Nat Rev Microbiol. 2014;12(10):661-72.

16. Helmink BA, Khan MAW, Hermann A, Gopalakrishnan V, Wargo JA. The microbiome, cancer, and cancer therapy. Nat Med. 2019:25(3):377-88.

17. Eliot MN, Michaud DS, Langevin SM, McClean MD, Kelsey KT. Periodontal disease and mouthwash use are risk factors for head and neck squamous cell carcinoma. Cancer Causes Control. 2013;24(7):1315-22.

18. Zeng XT, Xia LY, Zhang YG, Li S, Leng WD, Kwong JS. Periodontal disease and incident lung cancer risk: a meta-analysis of cohort studies. J Periodontol. 2016;87(10):1158-64.

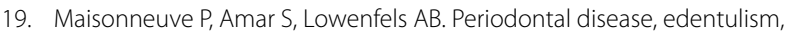
and pancreatic cancer: a meta-analysis. Ann Oncol. 2017;28(5):985-95.

20. Öğrendik M. Periodontal pathogens in the etiology of pancreatic cancer. Gastrointest Tumors. 2017;3(3-4):125-7.

21. Sun J, Zhou M, Salazar CR, Hays R, Bedi S, Chen Y, et al. Chronic periodontal disease, periodontal pathogen colonization, and increased risk of precancerous gastric lesions. J Periodontol. 2017;88(11):1124-34.

22. Koliarakis I, Messaritakis I, Nikolouzakis TK, Hamilos G, Souglakos J, Tsiaoussis J. Oral bacteria and intestinal dysbiosis in colorectal cancer. Int J Mol Sci. 2019;20(17):4146.

23. Michaud DS, Kelsey KT, Papathanasiou E, Genco CA, Giovannucci E. Periodontal disease and risk of all cancers among male never smokers: an updated analysis of the Health Professionals Follow-up Study. Ann Oncol. 2016:27(5):941-7.

24. Dizdar O, Hayran M, Guven DC, Yilmaz TB, Taheri S, Akman AC, et al. Increased cancer risk in patients with periodontitis. Curr Med Res Opin. 2017;33(12):2195-200.

25. Markowski MC, Boorjian SA, Burton JP, Hahn NM, Ingersoll MA, Maleki Vareki $\mathrm{S}$, et al. The microbiome and genitourinary cancer: a collaborative review. Eur Urol. 2019:75(4):637-46.

26. Hanahan D, Weinberg RA. Hallmarks of cancer: the next generation. Cell. 2011;144(5):646-74.

27. Hanahan D, Weinberg RA. The hallmarks of cancer. Cell. 2000:100(1):57-70.

28. Yamashita Y, Takeshita T. The oral microbiome and human health. J Oral Sci. 2017;59(2):201-6.

29. Estemalik J, Demko C, Bissada NF, Joshi N, Bodner D, Shankar E, et al. Simultaneous detection of oral pathogens in subgingival plaque and prostatic fluid of men with periodontal and prostatic diseases. J Periodontol. 2017;88(9):823-9.

30. National Cancer Institute. Cancers by body location/system. 2021. https://www.cancer.gov/types/by-body-location. Accessed 10 July 2021.

31. Page RC, Eke PI. Case definitions for use in population-based surveillance of periodontitis. J Periodontol. 2007;78(Suppl 7):1387-99.

32. Eke PI, Page RC, Wei L, Thornton-Evans G, Genco RJ. Update of the case definitions for population-based surveillance of periodontitis. J Periodontol. 2012;83(12):1449-54.

33. Joshipura KJ, Douglass CW, Garcia RI, Valachovic R, Willett WC. Validity of a self-reported periodontal disease measure. J Public Health Dent. 1996;56(4):205-12.

34. Gilbert AD, Nuttall NM. Self-reporting of periodontal health status. Br Dent J. 1999;186(5):241-4.

35. Wiebe CB, Putnins EE. The periodontal disease classification system of the American Academy of Periodontology-an update. J Can Dent Assoc. 2000;66(11):594-7.

36. Joshipura KJ, Pitiphat W, Douglass CW. Validation of self-reported periodontal measures among health professionals. J Public Health Dent. 2002:62(2):115-21. 
37. LaMonte MJ, Hovey KM, Millen AE, Genco RJ, Wactawski-Wende J. Accuracy of self-reported periodontal disease in the Women's Health Initiative Observational Study. J Periodontol. 2014;85(8):1006-18.

38. Kim DH, Jeong SN, Lee JH. Chronic periodontal disease increases risk for prostate cancer in elderly individuals in South Korea: a retrospective nationwide population-based cohort study. J Cancer. 2020;11(16):4716-23.

39. Güven DC, Dizdar O, Akman AC, Berker E, Yekeduz E, Ceylan F, et al. Evaluation of cancer risk in patients with periodontal diseases. Turk J Med Sci. 2019;49(3):826-31.

40. Lee JH, Kweon HH, Choi JK, Kim YT, Choi SH. Association between periodontal disease and prostate cancer: results of a 12-year longitudinal cohort study in South Korea. J Cancer. 2017:8(15):2959-65.

41. Arora M, Weuve J, Fall K, Pedersen NL, Mucci LA. An exploration of shared genetic risk factors between periodontal disease and cancers: a prospective co-twin study. Am J Epidemiol. 2010;171(2):253-9.

42. Hujoel PP, Drangsholt M, Spiekerman C, Weiss NS. An exploration of the periodontitis-cancer association. Ann Epidemiol. 2003;13(5):312-6.

43. Hiraki A, Matsuo K, Suzuki T, Kawase T, Tajima K. Teeth loss and risk of cancer at 14 common sites in Japanese. Cancer Epidemiol Biomarkers Prev. 2008;17(5):1222-7.

44. Michaud DS, Liu Y, Meyer M, Giovannucci E, Joshipura K. Periodontal disease, tooth loss, and cancer risk in male health professionals: a prospective cohort study. Lancet Oncol. 2008;9(6):550-8.

45. Hwang IM, Sun LM, Lin CL, Lee CF, Kao CH. Periodontal disease with treatment reduces subsequent cancer risks. QJM. 2014;107(10):805-12.

46. Wen BW, Tsai CS, Lin CL, Chang YJ, Lee CF, Hsu CH, et al. Cancer risk among gingivitis and periodontitis patients: a nationwide cohort study. QJM. 2014;107(4):283-90.

47. Michaud DS, Lu J, Peacock-Villada AY, Barber JR, Joshu CE, Prizment AE, et al. Periodontal disease assessed using clinical dental measurements and cancer risk in the ARIC study. J Natl Cancer Inst. 2018;110(8):843-54.

48. Oh H, Lee DH, Giovannucci EL, Keum N. Gastric and duodenal ulcers, periodontal disease, and risk of bladder cancer in the Health Professionals Follow-up Study. Cancer Causes Control. 2020;31(4):383-91.

49. Nwizu NN, Marshall JR, Moysich K, Genco RJ, Hovey KM, Mai X, et al. Periodontal disease and incident cancer risk among postmenopausal women: results from the Women's Health Initiative Observational Cohort. Cancer Epidemiol Biomarkers Prev. 2017;26(8):1255-65.

50. Gao L, Xu T, Huang G, Jiang S, Gu Y, Chen F. Oral microbiomes: more and more importance in oral cavity and whole body. Protein Cell. 2018;9(5):488-500.

51. Dewhirst FE, Chen T, Izard J, Paster BJ, Tanner AC, Yu WH, et al. The human oral microbiome. J Bacteriol. 2010;192(19):5002-17.

52. Sharma N, Bhatia S, Sodhi AS, Batra N. Oral microbiome and health. AIMS Microbiol. 2018;4(1):42-66.

53. Nobbs AH, Jenkinson HF. Interkingdom networking within the oral microbiome. Microbes Infect. 2015;17(7):484-92.

54. Bowen WH, Burne RA, Wu H, Koo H. Oral biofilms: pathogens, matrix, and polymicrobial interactions in microenvironments. Trends Microbiol. 2018;26(3):229-42.

55. Marsh PD, Zaura E. Dental biofilm: ecological interactions in health and disease. J Clin Periodontol. 2017:44(Suppl 18):S12-22.

56. Integrative HMP (iHMP) Research Network Consortium. The integrative human microbiome project. Nature. 2019;569(7758):641-8.

57. Costalonga M, Herzberg MC. The oral microbiomeand the immunobiology of periodontal disease and caries. Immunol Lett. 2014;162(2 Pt A):22-38.

58. Willis JR, Gabaldón T. The human oral microbiome in health and disease: from sequences to ecosystems. Microorganisms. 2020;8(2):308.

59. Griffen AL, Beall CJ, Campbell JH, Firestone ND, Kumar PS, Yang ZK, et al. Distinct and complex bacterial profiles in human periodontitis and health revealed by 165 pyrosequencing. ISME J. 2012;6(6):1176-85.

60. Liu B, Faller LL, Klitgord N, Mazumdar V, Ghodsi M, Sommer DD, et al. Deep sequencing of the oral microbiome reveals signatures of periodontal disease. PLoS ONE. 2012;7(6):e37919.

61. Lepp PW, Brinig MM, Ouverney CC, Palm K, Armitage GC, Relman DA. Methanogenic Archaea and human periodontal disease. Proc Natl Acad Sci USA. 2004;101(16):6176-81.

62. Matarazzo F, Ribeiro AC, Feres M, Faveri M, Mayer MP. Diversity and quantitative analysis of Archaea in aggressive periodontitis and periodontally healthy subjects. J Clin Periodontol. 2011;38(7):621-7.
63. Brennan CA, Garrett WS. Fusobacterium nucleatum - symbiont, opportunist and oncobacterium. Nat Rev Microbiol. 2019;17(3):156-66.

64. Socransky SS, Haffajee AD, Cugini MA, Smith C, Kent RL Jr. Microbial complexes in subgingival plaque. J Clin Periodontol. 1998;25(2):134-44.

65. Atanasova KR, Yilmaz O. Prelude to oral microbes and chronic diseases: past, present and future. Microbes Infect. 2015;17(7):473-83.

66. Sampaio-Maia B, Caldas IM, Pereira ML, Perez-Mongiovi D, Araujo R. The oral microbiome in health and its implication in oral and systemic diseases. Adv Appl Microbiol. 2016;97:171-210.

67. Hajishengallis G, Darveau RP, Curtis MA. The keystone-pathogen hypothesis. Nat Rev Microbiol. 2012;10(10):717-25.

68. Zenobia C, Hajishengallis G. Porphyromonas gingivalis virulence factors involved in subversion of leukocytes and microbial dysbiosis. Virulence. 2015;6(3):236-43.

69. Liang S, Krauss JL, Domon H, McIntosh ML, Hosur KB, Qu H, et al. The C5a receptor impairs IL-12-dependent clearance of Porphyromonas gingivalis and is required for induction of periodontal bone loss. J Immunol. 2011;186(2):869-77.

70. Bainbridge B, Verma RK, Eastman C, Yehia B, Rivera M, Moffatt C, et al. Role of Porphyromonas gingivalis phosphoserine phosphatase enzyme SerB in inflammation, immune response, and induction of alveolar bone resorption in rats. Infect Immun. 2010;78(11):4560-9.

71. Hajishengallis G. Periodontitis: from microbial immune subversion to systemic inflammation. Nat Rev Immunol. 2015;15(1):30-44.

72. Park SR, Kim DJ, Han SH, Kang MJ, Lee JY, Jeong YJ, et al. Diverse Toll-like receptors mediate cytokine production by Fusobacterium nucleatum and Aggregatibacter actinomycetemcomitans in macrophages. Infect Immun. 2014;82(5):1914-20.

73. Ahn SH, Chun S, Park C, Lee JH, Lee SW, Lee TH. Transcriptome profiling analysis of senescent gingival fibroblasts in response to Fusobacterium nucleatum infection. PLoS ONE. 2017;12(11):e0188755.

74. Saito A, Kokubu E, Inagaki S, Imamura K, Kita D, Lamont RJ, et al. Porphyromonas gingivalis entry into gingival epithelial cells modulated by Fusobacterium nucleatum is dependent on lipid rafts. Microb Pathog. 2012;53(5-6):234-42.

75. Neilands J, Davies JR, Bikker FJ, Svensater G. Parvimonas micra stimulates expression of gingipains from Porphyromonas gingivalis in multi-species communities. Anaerobe. 2019;55:54-60.

76. Kachlany SC. Aggregatibacter actinomycetemcomitans leukotoxin: from threat to therapy. J Dent Res. 2010;89(6):561-70.

77. Rubinstein MR, Wang X, Liu W, Hao Y, Cai G, Han YW. Fusobacterium nucleatum promotes colorectal carcinogenesis by modulating E-cadherin/beta-catenin signaling via its FadA adhesin. Cell Host Microbe. 2013;14(2):195-206.

78. Chen Y, Peng Y, Yu J, Chen T, Wu Y, Shi L, et al. Invasive Fusobacterium nucleatum activates beta-catenin signaling in colorectal cancer via a TLR4/P-PAK1 cascade. Oncotarget. 2017;8(19):31802-14.

79. Liu XB, Gao ZY, Sun CT, Wen H, Gao B, Li SB, et al. The potential role of $P$. gingivalis in gastrointestinal cancer: a mini review. Infect Agent Cancer. 2019; 14:23

80. Ogrendik M. Oral bacteria in pancreatic cancer: mutagenesis of the $\mathrm{p} 53$ tumour suppressor gene. Int J Clin Exp Pathol. 2015;8(9):11835-6.

81. Nikoletopoulou V, Markaki M, Palikaras K, Tavernarakis N. Crosstalk between apoptosis, necrosis and autophagy. Biochim Biophys Acta. 2013;1833(12):3448-59.

82. Yilmaz O, Jungas T, Verbeke P, Ojcius DM. Activation of the phosphatidylinositol 3-kinase/Akt pathway contributes to survival of primary epithelial cells infected with the periodontal pathogen Porphyromonas gingivalis. Infect Immun. 2004;72(7):3743-51.

83. Ishikawa M, Yoshida K, Okamura H, Ochiai K, Takamura H, Fujiwara N, et al. Oral Porphyromonas gingivalis translocates to the liver and regulates hepatic glycogen synthesis through the Akt/GSK-3beta signaling pathway. Biochim Biophys Acta. 2013;1832(12):2035-43.

84. Martin M, Schifferle RE, Cuesta N, Vogel SN, Katz J, Michalek SM. Role of the phosphatidylinositol 3 kinase-Akt pathway in the regulation of IL-10 and IL-12 by Porphyromonas gingivalis lipopolysaccharide. J Immunol. 2003;171(2):717-25.

85. Park SY, Park DJ, Kim YH, Kim Y, Choi YW, Lee SJ. Schisandra chinensis alpha-iso-cubebenol induces heme oxygenase-1 expression through PI3K/Akt and Nrf2 signaling and has anti-inflammatory activity in 
Porphyromonas gingivalis lipopolysaccharide-stimulated macrophages. Int Immunopharmacol. 2011;1 1(11):1907-15.

86. Hajishengallis $\mathrm{G}$, Wang M, Liang $\mathrm{S}$. Induction of distinct TLR2-mediated proinflammatory and proadhesive signaling pathways in response to Porphyromonas gingivalis fimbriae. J Immunol. 2009;182(11):6690-6.

87. Nakayama M, Inoue T, Naito M, Nakayama K, Ohara N. Attenuation of the phosphatidylinositol 3-kinase/Akt signaling pathway by Porphyromonas gingivalis gingipains RgpA, RgpB, and Kgp. J Biol Chem. 2015:290(8):5190-202.

88. Mao $S$, Park Y, Hasegawa Y, Tribble GD, James $C E$, Handfield M, et al. Intrinsic apoptotic pathways of gingival epithelial cells modulated by Porphyromonas gingivalis. Cell Microbiol. 2007;9(8):1997-2007.

89. Li Q, Pan C, Teng D, Lin L, Kou Y, Haase EM, et al. Porphyromonas gingivalis modulates Pseudomonas aeruginosa-induced apoptosis of respiratory epithelial cells through the STAT3 signaling pathway. Microbes Infect. 2014;16(1):17-27.

90. Stathopoulou PG, Galicia JC, Benakanakere MR, Garcia CA, Potempa J, Kinane DF. Porphyromonas gingivalis induce apoptosis in human gingival epithelial cells through a gingipain-dependent mechanism. BMC Microbiol. 2009:9:107.

91. Xue B, Xie Y, Xue Y, Hu N, Zhang G, Guan H, et al. Involvement of P2X7 receptors in retinal ganglion cell apoptosis induced by activated Muller cells. Exp Eye Res. 2016;153:42-50.

92. Yilmaz O, Yao L, Maeda K, Rose TM, Lewis EL, Duman M, et al. ATP scavenging by the intracellular pathogen Porphyromonas gingivalis inhibits P2X7-mediated host-cell apoptosis. Cell Microbiol. 2008;10(4):863-75.

93. Su Y, Chen C, Guo L, Du J, Li X, Liu Y. Ecological balance of oral microbiota is required to maintain oral mesenchymal stem cell homeostasis. Stem Cells. 2018;36(4):551-61.

94. Lee J, Roberts JS, Atanasova KR, Chowdhury N, Han K, Yilmaz O. Human primary epithelial cells acquire an epithelial-mesenchymal-transition phenotype during long-term infection by the oral opportunistic pathogen, Porphyromonas gingivalis. Front Cell Infect Microbiol. 2017;7:493. https://doi.org/10.3389/fcimb.2017.00493.

95. Zhang S, Li C, Liu J, Geng F, Shi X, Li Q, et al. Fusobacterium nucleatum promotes epithelial-mesenchymal transiton through regulation of the IncRNA MIR4435-2HG/miR-296-5p/Akt2/SNAl1 signaling pathway. FEBS J. 2020:287(18):4032-47.

96. Inaba H, Sugita H, Kuboniwa M, Iwai S, Hamada M, Noda T, et al. Porphyromonas gingivalis promotes invasion of oral squamous cell carcinoma through induction of proMMP9 and its activation. Cell Microbiol. 2014:16(1):131-45.

97. Harrandah AM, Chukkapalli SS, Bhattacharyya I, Progulske-Fox A, Chan EKL. Fusobacteria modulate oral carcinogenesis and promote cancer progression. J Oral Microbiol. 2020;13(1):1849493.

98. Fleetwood AJ, Lee MKS, Singleton W, Achuthan A, Lee MC, O'BrienSimpson NM, et al. Metabolic remodeling, inflammasome activation, and pyroptosis in macrophages stimulated by porphyromonas gingivalis and its outer membrane vesicles. Front Cell Infect Microbiol. 2017;7:351. https://doi.org/10.3389/fcimb.2017.00351.

99. Borba TT, Molz P, Schlickmann DS, Santos C, Oliveira CF, Pra D, et al. Periodontitis: genomic instability implications and associated risk factors. Mutat Res Genet Toxicol Environ Mutagen. 2019;840:20-3. https://doi. org/10.1016/j.mrgentox.2019.01.005.

100. Teshima R, Hanada K, Akada J, Kawano K, Yamaoka Y. Aggregatibacter actinomycetemcomitans infection causes DNA double-strand breaks in host cells. Genes Cells. 2018:23(4):264-73.

101. Tahara T, Yamamoto E, Suzuki H, Maruyama R, Chung W, Garriga J, et al. Fusobacterium in colonic flora and molecular features of colorectal carcinoma. Cancer Res. 2014;74(5):1311-8.

102. Suthin K, Matsushita K, Machigashira M, Tatsuyama S, Imamura T, Torii $M$, et al. Enhanced expression of vascular endothelial growth factor by periodontal pathogens in gingival fibroblasts. J Periodontal Res. 2003;38(1):90-6.

103. Szabo C, Coletta C, Chao C, Modis K, Szczesny B, Papapetropoulos A, et al. Tumor-derived hydrogen sulfide, produced by cystathionine-betasynthase, stimulates bioenergetics, cell proliferation, and angiogenesis in colon cancer. Proc Natl Acad Sci USA. 2013;110(30):12474-9.

104. Akhmatova NK, Egorova NB, Kurbatova EA, Akhmatov EA. Activation of innate immunity by bacterial ligands of toll-like receptors. Front Immunol. 2014:5:89.
105. Grivennikov SI, Greten FR, Karin M. Immunity, inflammation, and cancer. Cell. 2010;140(6):883-99.

106. Liu T, Zhang L, Joo D, Sun SC. NF-KB signaling in inflammation. Signal Transduct Target Ther. 2017;2:17023.

107. Milward MR, Chapple IL, Wright HJ, Millard JL, Matthews JB, Cooper PR. Differential activation of NF-kappaB and gene expression in oral epithelial cells by periodontal pathogens. Clin Exp Immunol. 2007;148(2):307-24.

108. Hoesel B, Schmid JA. The complexity of NF-kappaB signaling in inflammation and cancer. Mol Cancer. 2013;12:86.

109. Al-Hebshi NN, Borgnakke WS, Johnson NW. The microbiome of oral squamous cell carcinomas: a functional perspective. Curr Oral Health Rep. 2019;6(2):145-60.

110. Muenst S, Laubli H, Soysal SD, Zippelius A, Tzankov A, Hoeller S. The immune system and cancer evasion strategies: therapeutic concepts. J Intern Med. 2016;279(6):541-62.

111. Gur C, Ibrahim Y, Isaacson B, Yamin R, Abed J, Gamliel M, et al. Binding of the Fap2 protein of Fusobacterium nucleatum to human inhibitory receptor TIGIT protects tumors from immune cell attack. Immunity. 2015:42(2):344-55.

112. Bourgeois D, Inquimbert C, Ottolenghi L, Carrouel F. Periodontal pathogens as risk factors of cardiovascular diseases, diabetes, rheumatoid arthritis, cancer, and chronic obstructive pulmonary disease-is there cause for consideration? Microorganisms. 2019;7(10):424.

113. Blanc V, O'Valle F, Pozo E, Puertas A, Leon R, Mesa F. Oral bacteria in placental tissues: increased molecular detection in pregnant periodontitis patients. Oral Dis. 2015;21(7):905-12.

114. Fischer LA, Demerath E, Bittner-Eddy P, Costalonga M. Placental colonization with periodontal pathogens: the potential missing link. Am J Obstet Gynecol. 2019;221(5):383-92.e3. https://doi.org/10.1016/j.ajog. 2019.04.029.

115. Dominy SS, Lynch C, Ermini F, Benedyk M, Marczyk A, Konradi A, et al. Porphyromonas gingivalis in Alzheimer's disease brains: evidence for disease causation and treatment with small-molecule inhibitors. Sci Adv. 2019:5(1):eaau3333.

116. Harada F, Uehara O, Morikawa T, Hiraki D, Onishi A, Toraya S, et al. Effect of systemic administration of lipopolysaccharides derived from Porphyromonas gingivalis on gene expression in mice kidney. Med Mol Morphol. 2018;51(3):156-65.

117. Katz J, Yang QB, Zhang P, Potempa J, Travis J, Michalek SM, et al. Hydrolysis of epithelial junctional proteins by Porphyromonas gingivalis gingipains. Infect Immun. 2002;70(5):2512-8

118. Kikuchi Y, Kimizuka R, Kato T, Okuda K, Kokubu E, Ishihara K. Treponema denticola induces epithelial barrier dysfunction in polarized epithelial cells. Bull Tokyo Dent Coll. 2018;59(4):265-75.

119. Hajishengallis $G$, Chavakis T. Local and systemic mechanisms linking periodontal disease and inflammatory comorbidities. Nat Rev Immunol. 2021;56:1-5.

120. Coussens LM, Werb Z. Inflammation and cancer. Nature. 2002;420(6917):860-7.

121. Rani A, Dasgupta P, Murphy JJ. Prostate cancer: the role of inflammation and chemokines. Am J Pathol. 2019;189(11):2119-37.

122. Gakis G. The role of inflammation in bladder cancer. Adv Exp Med Biol. 2014;816:183-96.

123. de Vivar Chevez AR, Finke J, Bukowski R. The role of inflammation in kidney cancer. Adv Exp Med Biol. 2014;816:197-234.

124. Saranyutanon S, Deshmukh SK, Dasgupta S, Pai S, Singh S, Singh AP. Cellular and molecular progression of prostate cancer: models for basic and preclinical research. Cancers (Basel). 2020;12(9):2651. https://doi. org/10.3390/cancers12092651.

125. Hajishengallis G. Immunomicrobial pathogenesis of periodontitis: keystones, pathobionts, and host response. Trends Immunol. 2014;35(1):3-11.

126. Elinav E, Nowarski R, Thaiss CA, Hu B, Jin C, Flavell RA. Inflammationinduced cancer: crosstalk between tumours, immune cells and microorganisms. Nat Rev Cancer. 2013;13(11):759-71.

\section{Publisher's Note}

Springer Nature remains neutral with regard to jurisdictional claims in published maps and institutional affiliations. 